Review Article

\title{
Nontuberculous Mycobacteria Isolation from Clinical and Environmental Samples in Iran: Twenty Years of Surveillance
}

\author{
Ali Akbar Velayati, ${ }^{1}$ Parissa Farnia, ${ }^{1}$ Mohadese Mozafari, ${ }^{1}$ and Mehdi Mirsaeidi ${ }^{2}$ \\ ${ }^{1}$ Mycobacteriology Research Centre, National Research Institute of Tuberculosis and Lung Disease (NRITLD), \\ Shahid Beheshti University of Medical Sciences, P.O. Box 19575-154, Tehran 19569-44413, Iran \\ ${ }^{2}$ Section of Pulmonary, Critical Care, Sleep and Allergy Department of Medicine M/C 719, University of Illinois at Chicago, \\ 840 S. Wood Street, Chicago, IL 60612-7323, USA
}

Correspondence should be addressed to Parissa Farnia; pfarnia@hotmail.com

Received 27 July 2014; Accepted 17 September 2014

Academic Editor: Stefano Aliberti

Copyright (C) 2015 Ali Akbar Velayati et al. This is an open access article distributed under the Creative Commons Attribution License, which permits unrestricted use, distribution, and reproduction in any medium, provided the original work is properly cited.

\begin{abstract}
Nontuberculous mycobacteria (NTM) are opportunistic pathogens that are widely distributed in the environment. There is a lack of data on species distribution of these organisms from Iran. This study consists of a review of NTM articles published in Iran between the years 1992 and 2014. In this review, 20 articles and 14 case reports were identified. Among the 20 articles, 13 (65\%) studies focused on NTM isolates from clinical specimens, 6 (30\%) studies examined NTM isolates from environmental samples, and one (5\%) article included both clinical and environmental isolates. M. fortuitum (229/997; 23\%) was recorded as the most prevalent and rapid growing mycobacteria (RGM) species in both clinical (28\%) and environmental (19\%) isolated samples $(P<$ 0.05). Among slow growing mycobacteria (SGM), M. simiae (103/494; 21\%) demonstrated a higher frequency in clinical samples whereas in environmental samples it was $M$. flavescens (44/503; 9\%). These data represent information from 14 provinces out of 31 provinces of Iran. No information is available in current published data on clinical or environmental NTM from the remaining 17 provinces in Iran. These results emphasize the potential importance of NTM as well as the underestimation of NTM frequency in Iran. NTM is an important clinical problem associated with significant morbidity and mortality in Iran. Continued research is needed from both clinical and environmental sources to help clinicians and researchers better understand and address NTM treatment and prevention.
\end{abstract}

\section{Introduction}

In 1996, the Working Group of the Bacteriology and Immunology Section of the International Union against Tuberculosis and Lung Disease contacted 50 laboratories in several countries, including Iran, in order to collect and analyze epidemiological data for nontuberculous mycobacteria (NTM) or mycobacteria other than tuberculosis (MOTT). At this time, the Iranian reference laboratory provided data from 98 patients (1980-1983), of which M. fortuitum and M. kansasii were identified as the most dominant NTM in clinical samples [1]. In the following years, many researchers attempted to determine the prevalence of NTM and its importance in Iran [2-4]. Unfortunately, these studies failed to capture a comprehensive measure of NTM in Iran. The majority of
NTM in Iran consist of small samples or data confined to small geographical areas that cannot be generalized. As a result, no clear data on the epidemiology of NTM is available on the national scale.

Iran is an intermediate tuberculosis- (TB-) burden country where $\mathrm{TB}$ remains a major public health problem. The incidence of TB in Iran is 21 per 100,000 people.

The significant number of multi-drug resistant (MDR), extensive drug resistant (XDR), and totally drug resistant (TDR) tuberculosis underline the possibility of NTM infection among tuberculosis suspected cases $[5,6]$. In most cases, patients with positive sputum smear microscopy are treated with first line pulmonary tuberculosis therapy. Clinical failures prompt the transfer of TB samples to central laboratories for further identification of isolates and in case 
of NTM infection. Therefore, the diagnosis and treatment of resistant TB begin with considerable delay [7]. So far, limited investigation on NTM infections is reported from TB endemic countries with limited laboratory resources. Instead, NTM infection is more documented in developed countries including geographical variability [8-10]. For example, Mycobacterium avium complex (MAC) followed by $M$. gordonae and $M$. xenopi is considered the most predominant NTM in the United States and Europe $[11,12]$. Given the complex treatment challenges particularly in low resource countries, understanding geographical diversity of NTM within the country is particularly important. With this background, we aim to retrospectively analyze and compare the NTM data published in the last 20 years. In addition, we evaluated the long-term trends of NTM isolation from clinical and environmental specimens.

\section{Methods}

A literature search was performed in PubMed, Scopus, SID and Google Scholar, Embase, and the Cochrane Library on nontuberculous mycobacteria in Iran. The search keywords were "atypical Mycobacteria," "nontuberculous mycobacteria," and "Iran," Original articles, case reports, and reviews published on nontuberculous mycobacteria in Iran in peerreviewed journals including Persian and English journals were considered $[2-4,13-40]$. Congress abstracts were excluded. The following data were abstracted for the purpose of review: the name of the city, research methods, and individual NTM species as well as sample source. The statistical significance of observed trends of NTM in the last 20 years was tested using Poisson log-linear regression. All analyses were performed using the statistical software packages SPSS version 21 (IBM SPSS, Inc., Chicago, IL).

\section{Results}

Twenty original articles about NTM isolates were identified. The selected articles were published from 1992 to 2014. The majority of these articles $(13 / 20 ; 65 \%)$ included data from clinical samples, six studies outlined the frequency of NTM in the environment, and a single (5\%) article studied both clinical and environmental NTM (Figure 1). The geographical setting of these studies was Tehran in 6 articles (30\%), Isfahan in $6(30 \%)$, Khuzestan in $2(10 \%)$, and Golestan in $2(10 \%)$. The remaining articles included provinces such as Sistan and Baluchestan (1/20; 5\%), Kerman (1/20; 5\%), West Azerbaijan $(1 / 20 ; 5 \%)$, and Gilan $(1 / 20 ; 5 \%)$ (Table 1$)$.

Among 14 case report articles from different cities of Iran, 4 were reported from Tehran (28.5\%), 3 from Isfahan (21.4\%), 2 from Sari $(14.2 \%)$, and one from other cities including Shiraz (7.1\%), Khomein (7.1\%), Babol (7.1\%), Ilam (7.1\%), and Karaj (7.1\%) (Table 2).

The majority of NTM species with known sources were isolated from respiratory specimens including sputum (134/494; 27.1\%), bronchoalveolar lavage (51/494; 10.3\%), bronchial washing $(7 / 494 ; 1.4 \%)$, pleural samples $(6 / 494$; $1.2 \%)$, and lung tissue biopsy $(5 / 494 ; 1 \%)$. Extrapulmonary samples were collected from urine $(9 / 494 ; 1.8 \%)$, abscess
(6/494; $1.2 \%)$, lymph node biopsy $(4 / 494 ; 0.8 \%)$, gastric lavage $(2 / 494 ; 0.4 \%)$, vaginal discharge $(2 / 494 ; 0.4 \%)$, CSF $(1 / 494 ; 0.2 \%)$, dermal lesion $(3 / 494 ; 0.6 \%)$, subcutaneous nodule in hand or finger $(4 / 494 ; 0.8 \%)$, and corneal biopsy $(1 / 494 ; 0.2 \%)$. In a considerable number of reports $(259 / 494$; $52.4 \%)$, the sources of isolation were not documented.

As shown in Table 1, the primary method of NTM detection was based on culture using Löwenstein-Jensen media. Identification was performed by conventional methods in $38 \%(8 / 20)$ and molecular methods in $15 \%(3 / 20)$ of articles. In $9(45 \%)$ studies, both molecular and conventional methods were applied.

3.1. NTM in Clinical Samples. The geographic locations of samples were mainly Tehran $(261 / 480 ; 54.3 \%)$, Isfahan (153/480; 31.8\%), Khuzestan (34/480; 7.1\%), Golestan (19/480; $3.9 \%)$, Kermanshah (7/480; $1.4 \%)$, Kerman (3/480; 0.6\%), and Sistan-Baluchestan (3/480; 0.6\%). From 13 studies using clinical samples, 480 NTM species were isolated. Of these isolates, 269 (56\%) were grouped as SGM and 211 (43.9\%) as RGM. The most prevalent RGM in clinical samples was $M$. fortuitum $(136 / 480 ; 28.3 \%)$ in all locations (Isfahan 105/153, $68.6 \%$, Khuzestan 9/34, 26.4\%, and Golestan 4/19, 21\%) except for Tehran. The prevalence of RGM was $M$. chelonae $(29 / 261 ; 11.1 \%)$ in Tehran. Among SGM species, M. simiae $(103 / 480 ; 21.4 \%)$ showed the highest rate. Geographical distribution of SGM in clinical samples was $M$. simiae in Tehran $(88 / 261 ; 33.7 \%)$ and Golestan $(6 / 19 ; 31.5 \%)$, M. gordonae $(16 / 153 ; 10.4 \%)$ in Isfahan, and M. intracellulare $(6 / 34 ; 17.6 \%)$ in Khuzestan (Table 3).

In the case report articles, $M$. marinum $(4 / 14 ; 28.5 \%)$ had higher detection rate, most frequently isolated from nodules or lesions of the hand (Table 2 ).

3.2. NTM in Environmental Samples. Data regarding environmental distribution of NTM were primarily from Tehran (193/503; 38.3\%), Isfahan (51/503; 10.1\%), Golestan (161/503; $32 \%)$, West Azerbaijan (65/503; 12.9\%), and Gilan (33/503; $6.5 \%)$. In total, 503 NTM from environmental samples were isolated, which included 221 (43.9\%) SGM and 282 (56\%) RGM. Among RGM species, M. fortuitum (93/503; $18.4 \%$ ) showed higher frequency in environmental samples in different locations including Golestan (35/161; 21.7\%), West Azerbaijan (21/65; 32.3\%), Isfahan (20/51; 39.2\%), Tehran $(10 / 193 ; 5.1 \%)$, and Gilan $(7 / 33 ; 21.2 \%)$ (Table 4). Regardless of geographical locations, the frequency of $M$. fortuitum was high in both water $(195 / 503 ; 38.7 \%)$ and soil $(308 / 503 ; 61.2 \%)$ samples. SGM frequencies varied in different locations; in Gilan M. terrae was $11 / 33,33.3 \%$, in Golestan $M$. triviale was $10 / 161,6.2 \%$, and in Isfahan M. gordonae was 7/51, 13.7 .

3.3. Trends of NTM. As shown in Figure 2, the frequency of NTM among pulmonary TB cases was studied in only 8 studies. In 1995, 18 (8\%) of 225 respiratory samples were recorded as NTM as compared to 2013 when 55 (18\%) were recorded as NTM from 291 samples. This trend shows a significant increase in NTM detection rates during the study period $(P<0.05)$. 


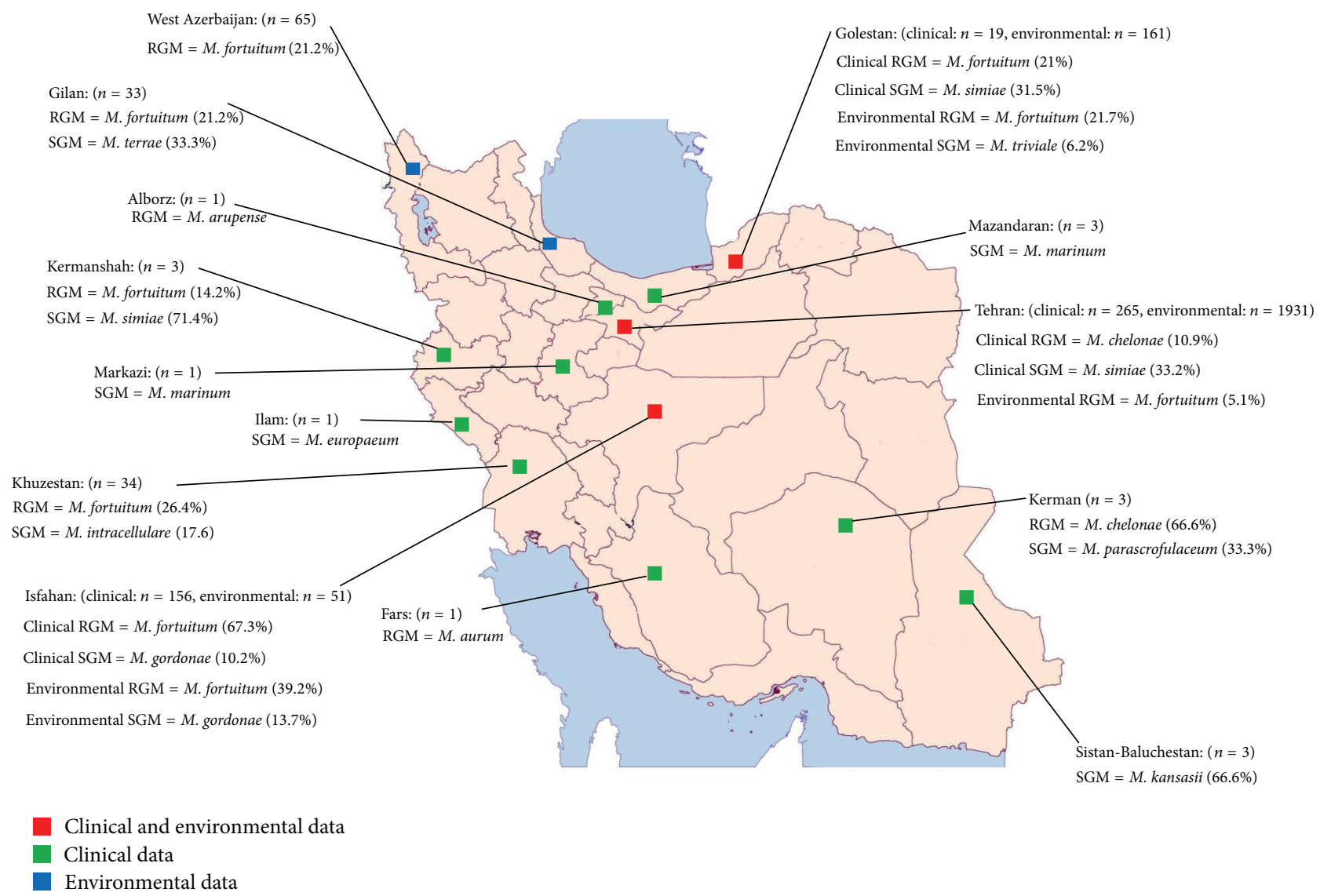

FIGURE 1: The provinces of Iran which work on NTM in clinical or environmental samples. The most prevalent SGM and RGM were noted.

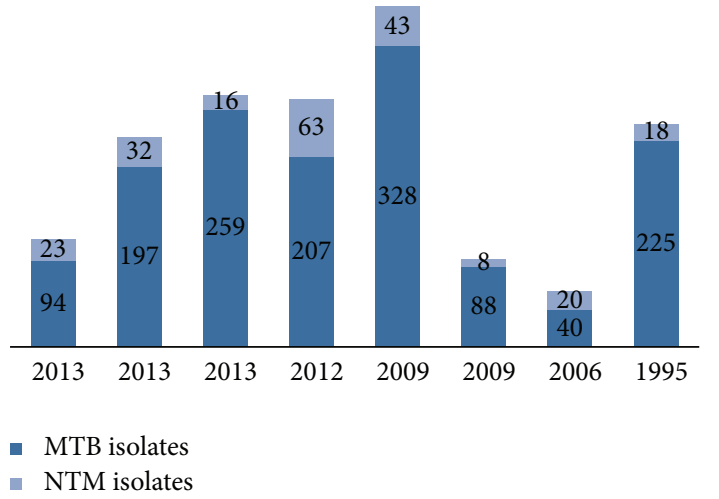

FIGURE 2: Number of NTM and MTB isolates in 8 studies.

\section{Discussion}

To the best of our knowledge this is the first study in which trends in clinical and environmental NTM species have been investigated over the past twenty years. Overall, from 34 published reports (original and case reports), 997 NTM strains were identified (494 isolated from clinical samples and 503 from environmental samples). The majority of clinical (86.2\%) and environmental (65.2\%) NTM species were isolated from Tehran $(n=261)$ and Isfahan $(n=53)$, respectively. These data are incomplete considering that Iran consists of 31 provinces. Here, we showed that NTM was isolated only from $14(46 \%)$ provinces during the past years (Figure 1). In the remaining 17 provinces, there is no data available on prevalence of environmental and clinical NTM. These numbers suggest that NTM is a neglected disease in Iran, which is likely true for other neighboring countries in the region, where the incidence of $\mathrm{TB}$ is higher, such as Afghanistan, Iraq, and Pakistan [41-48]. In Pakistan, three clinical NTM reports were published in 1984, 2011, and 2013 with total sample size of 4, 62, and 104 subjects, respectively $[43,44]$. M. fortuitum was identified as the most prevalent NTM in Pakistan (13.5\%). In Iraq, few studies recently reported the frequency of NTM in dairy products and environmental samples such as milk powder and fresh milk, drinking water, and fecal samples from horses [46-48]. The most prevalent NTM species in Iraq was M. chelonae $(18.2 \%)[46,48]$.

In this study we also aimed to identify NTM distribution and trends within Iran. Variable techniques were used in different laboratories. From 1992 to 2006, most laboratories used traditional methods for identification of NTM in both clinical and environmental samples. However, from 2009 to 2014, advances in laboratory technique allowed combinations 


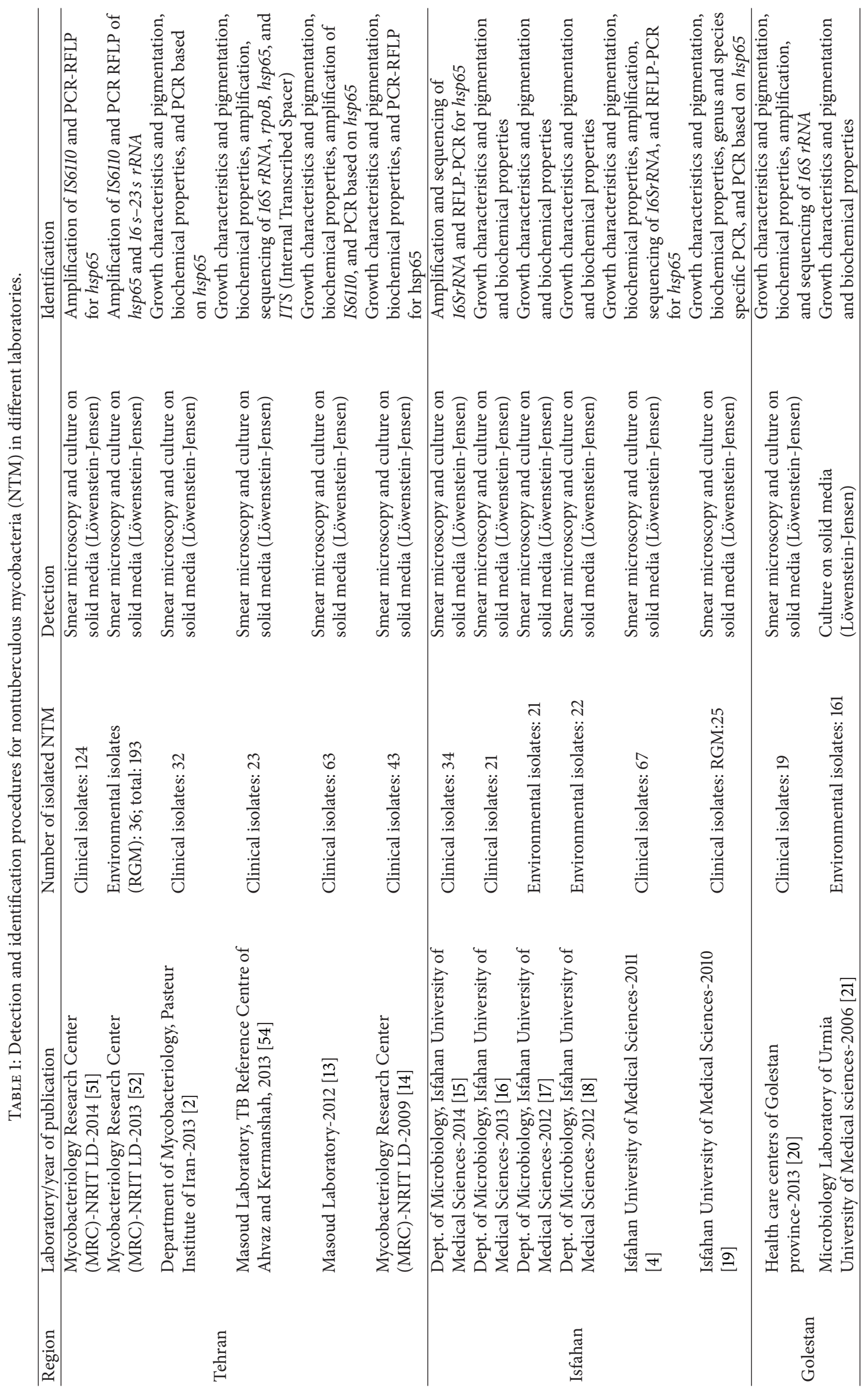




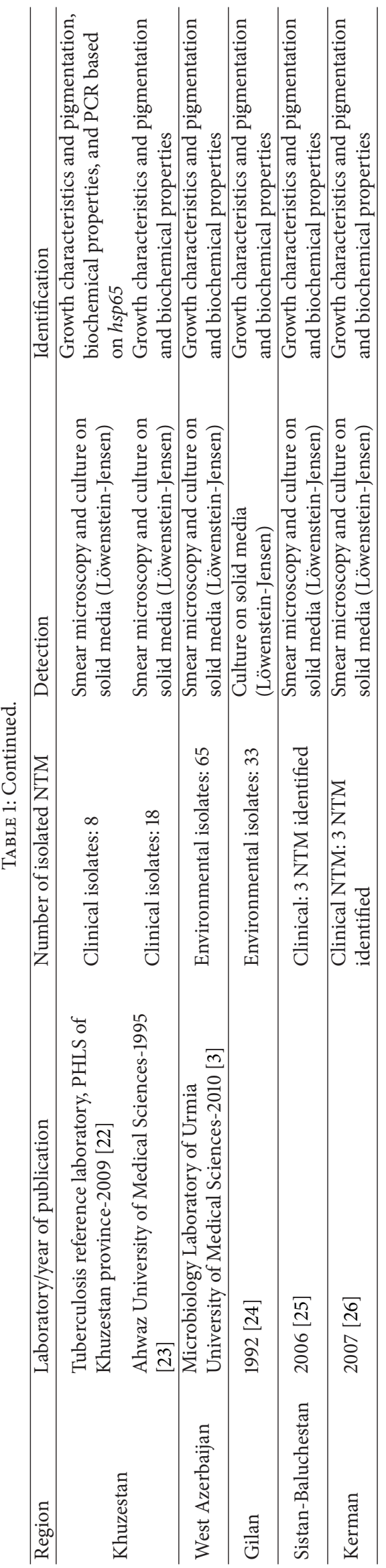


TABLE 2: Case report studies of Iran.

\begin{tabular}{llcc}
\hline Species & Year & City & Infected organ \\
\hline Mycobacteriumbranderi [27] & 2014 & Tehran & Bone marrow \\
Mycobacterium marinum [28] & 2014 & Sari & Papule-hand \\
Mycobacterium iranicum [29] & 2013 & Isfahan & Bronchoalveolar lavage/hand wound \\
Mycobacterium arupense [30] & 2013 & Karaj & Respiratory system and blood \\
Mycobacterium chelonae [31] & 2013 & Tehran & Sputum and cervical lymph node \\
Mycobacterium aurum [32] & 2012 & Shiraz & Corneal biopsy \\
Mycobacterium europaeum [33] & 2012 & Ilam & Sputum \\
Mycobacterium marinum [34] & 2011 & Khomein & Nodule on the dorsum of fourth finger \\
Mycobacterium marinum [35] & 2011 & Isfahan & Lesions and pustules of the right forearm \\
Mycobacterium monacence [36] & 2012 & Isfahan & Sputum \\
Mycobacterium parascrofulaceum [37] & 2011 & Tehran & Vaginal discharge \\
Mycobacterium lentiflavum [38] & 2010 & Sari & Sputum \\
Mycobacterium marinum [39] & 2008 & Tehran & Nodules and bulls on the back of the right hand \\
Mycobacterium thermoresistibile [40] & 2006 & Cervical lymph node
\end{tabular}

of traditional and molecular methods to be used (Table 1) resulting in the detection of more species of NTM in clinical and environmental samples. Reports from high-tech laboratories proposed the use of commercial line probe assay supplemented with sequencing for identification $[49,50]$. Ideally, the use of the commercial method may support standardization and it facilitates the comparison of results within different settings. Our data demonstrate PRA (PCR restriction analysis) methods with either $h s p 65$ or $16 s-23 s$ $r R N A, r p o B$ genes as the optional molecular test [18, 51, 52]. This highlights the need for standardized methods and guidelines for NTM identification in Iran.

We also showed that the majority of NTM were collected from respiratory samples. The results underline the importance of identifying NTM from suspected pulmonary TB patients. Molecular and phenotypic identification revealed a geographical distribution of NTM in Iran. From 494 clinical NTM isolates, $28.3 \%$ and $21.4 \%$ were recorded to be $M$. fortuitum and $M$. simiae, respectively. Analyzing the previous studies [15-19] showed geographical differences for $M$. fortuitum distribution, where Isfahan had the highest prevalence of $M$. fortuitum (105/153; 68.6\%), while in Tehran the prevalence rate was less than $10 \%(17 / 261 ; 6.5 \%)(P>$ $0.05)$. These results make the analysis a bit difficult, as we are not sure if the report is a laboratory cross contamination or if it is $M$. fortuitum endemicity in some parts of Iran.

The results from environmental samples also showed the high frequency of $M$. fortuitum (93/282; 32.4\%) followed by M. chelonae $(38 / 282 ; 13.4 \%)$ in water and soil samples. This suggests the possible risk of $M$. fortuitum transmission from nature to human. Among SGM species, M. simiae isidentified as the dominant NTM in Tehran $(88 / 261 ; 33.7 \%)$ and Golestan provinces $(6 / 19 ; 31.5 \%)[20,53,54]$. In three other regional settings (Isfahan, Sistan-Baluchestan, and Kerman), $M$. simiae was not isolated. The clinical importance of $M$. simiae in various geographical regions of Asia, including
Turkey and Japan, has been already documented $[55,56]$. The frequency of $M$. simiae wasreported to be from $1.5 \%$ to $10 \%$ across studies $[53,54]$. For environmental SGM, the frequency of $M$. flavescens (44/503; 9\%), M. thermoresistibile $(24 / 503 ; 5 \%)$, and $M$. terrae $(21 / 503 ; 5 \%)$ was higher than other species (Table 4). In contrast to RGM group, the distribution and frequency of slow growing mycobacteria in clinical and environmental samples were different.

The current study found a considerable number of environmental NTM $(157 / 503 ; 31.2 \%)$ that remained unidentifiable (Table 3). This highlights the importance of the implementation of new techniques in order to improve NTM identification. At present, 8 regional and one national reference TB laboratories are functioning in Iran. Recently, due to global fund, they have been equipped with molecular diagnostic testing capabilities. As a result, it is our expectation that NTM detection will increase within the next few years.

Drug susceptibility tests (DST) for NTM were not performed in the majority of published studies in Iran. In developed countries, a variety of susceptibility testing methods such as the E-test, TREK, and microbroth dilution are used to carry out DST [57]. Given the well-described resistance patterns emerging in developed countries with low incidence of NTM, susceptibility testing is a particularly important clinical tool for countries such as Iran.

In conclusions, the trends of isolation and identification of NTM have been increased in Iran in the last 20 years. This increasing trend is attributable to the implementation of enhanced molecular techniques that have improved the detection coupled with the enhanced awareness of NTM in the clinical setting. However, further research is needed to address this important public health threat including enhancing the epidemiology of NTM throughout Iran, standardizing laboratory techniques for detection and drug susceptibility testing, and improving clinicians knowledge on NTM diagnosis and treatment in Iran. 
TABLE 3: Species distribution of clinical nontuberculous mycobacteria isolated in articles reported from Iran.

\begin{tabular}{|c|c|c|c|c|c|c|c|c|}
\hline Species & $\begin{array}{l}\text { Kermanshah } \\
\quad(2013)\end{array}$ & $\begin{array}{c}\text { Kerman } \\
(2007)\end{array}$ & $\begin{array}{c}\text { Isfahan } \\
(2010-2014)\end{array}$ & $\begin{array}{l}\text { Khuzestan } \\
(1995-2009)\end{array}$ & $\begin{array}{c}\text { Tehran } \\
(2009-2014)\end{array}$ & $\begin{array}{c}\text { Sistan- } \\
\text { Baluchestan } \\
(2006)\end{array}$ & $\begin{array}{l}\text { Golestan } \\
(2013)\end{array}$ & Total \\
\hline M. fortuitum & 1 & & 105 & 9 & 17 & & 4 & 136 \\
\hline M. simiae & 5 & & & 4 & 88 & & 6 & 103 \\
\hline M. kansasii & 1 & & 14 & 2 & 38 & 2 & & 57 \\
\hline M. gordonae & & & 16 & 5 & 19 & & 1 & 41 \\
\hline M. chelonae & & 2 & & & 29 & & 1 & 32 \\
\hline M. intracellulare & & & 2 & 6 & 11 & & & 19 \\
\hline M. abscessus & & & & & 17 & & & 17 \\
\hline M. scrofulaceum & & & & 1 & 7 & & & 8 \\
\hline M. avium & & & 1 & 3 & 1 & 1 & & 6 \\
\hline M. conceptionence & & & 3 & & 2 & & & 5 \\
\hline M. marinum & & & & & 1 & & 3 & 4 \\
\hline M. lentiflavum & & & 1 & & 2 & & 1 & 4 \\
\hline M. thermoresistibile & & & 1 & & 3 & & & 4 \\
\hline M. szulgai & & & & 2 & 1 & & & 3 \\
\hline M. branderi & & & & & 3 & & & 3 \\
\hline M. parascrofulaceum & & 1 & 1 & & 1 & & & 3 \\
\hline M. gastri & & & & & 2 & & 1 & 3 \\
\hline M. malmoense & & & & & 3 & & & 3 \\
\hline M. porcinum & & & 3 & & & & & 3 \\
\hline M. phlei & & & 2 & & 1 & & & 3 \\
\hline M. massiliense & & & & & 3 & & & 3 \\
\hline M. monacense & & & 1 & & 1 & & & 2 \\
\hline M. nonchromogenicum & & & & & 1 & & 1 & 2 \\
\hline M. senegalense & & & & & 2 & & & 2 \\
\hline M. genavense & & & & & 1 & & & 1 \\
\hline M. triviale & & & & 1 & & & & 1 \\
\hline M. sherrissii & & & & & 1 & & & 1 \\
\hline M. xenopi & & & & 1 & & & & 1 \\
\hline M. montefiorense & & & & & 1 & & & 1 \\
\hline M. triplex & & & & & 1 & & & 1 \\
\hline M. arupense & & & & & 1 & & & 1 \\
\hline M. nebraskense & & & & & 1 & & & 1 \\
\hline M. flavescens & & & & & & & 1 & 1 \\
\hline M. smegmatis & & & 1 & & & & & 1 \\
\hline M. austroafricanum & & & 1 & & & & & 1 \\
\hline M. elephantis & & & 1 & & & & & 1 \\
\hline M. novocastrencse & & & & & 1 & & & 1 \\
\hline M. aurum & & & & & 1 & & & 1 \\
\hline
\end{tabular}


TABLE 4: Species distribution of environmental nontuberculous mycobacteria isolated in articles reported from Iran.

\begin{tabular}{|c|c|c|c|c|c|c|}
\hline Species & $\begin{array}{c}\text { Isfahan } \\
(2012-2013) \\
\end{array}$ & $\begin{array}{c}\text { West Azerbaijan } \\
(2010)\end{array}$ & $\begin{array}{c}\text { Golestan } \\
(2006)\end{array}$ & Gilan (1992) & $\begin{array}{c}\text { Tehran } \\
(2013-2014) \\
\end{array}$ & Total \\
\hline M. fortuitum & 20 & 21 & 35 & 7 & 10 & 93 \\
\hline M. flavescens & 1 & 10 & 33 & & & 44 \\
\hline M. chelonae & 5 & 6 & 27 & & & 38 \\
\hline M. thermoresistable & & 4 & 20 & & & 24 \\
\hline M. terrae & 2 & & 8 & 11 & & 21 \\
\hline M. phlei & 1 & & 14 & & & 15 \\
\hline M. pregrinum & & 11 & & & 3 & 14 \\
\hline M. mucogenicum & 5 & 6 & & & 2 & 13 \\
\hline M. gordonae & 7 & & 4 & & & 11 \\
\hline M. triviale & & & 10 & & & 10 \\
\hline M. senegalense & & & & & 9 & 9 \\
\hline M. хепорi & 1 & & & 7 & & 8 \\
\hline M. avium & 1 & & & 6 & & 7 \\
\hline M. abscessus & 2 & 3 & & & 1 & 6 \\
\hline M. smegmatis & 4 & 2 & & & & 6 \\
\hline M. parafortuitum & & & & & 5 & 5 \\
\hline M. fallax & 1 & & 4 & & & 5 \\
\hline M. conceptionence & 1 & & & & 3 & 4 \\
\hline M. gastri & & & 3 & & & 3 \\
\hline M. kansasii & & & 1 & 2 & & 3 \\
\hline M. neoaurum & & 2 & & & & 2 \\
\hline M. marinum & & & 2 & & & 2 \\
\hline M. aurum & & & & & 1 & 1 \\
\hline M. poriferae & & & & & 1 & 1 \\
\hline M. obuense & & & & & 1 & 1 \\
\hline Unidentified SGM & & & & & 157 & 157 \\
\hline
\end{tabular}

\section{Conflict of Interests}

The authors declare that there is no conflict of interests regarding the publication of this paper.

\section{References}

[1] N. Martín-Casabona, A. R. Bahrmand, J. Bennedsen et al., "Non-tuberculous mycobacteria: patterns of isolation. A multicountry retrospective survey," International Journal of Tuberculosis and Lung Disease, vol. 8, no. 10, pp. 1186-1193, 2004.

[2] M. Saifi, E. Jabbarzadeh, A. R. Bahrmand et al., "HSP65PRA identification of non-tuberculosis mycobacteria from 4892 samples suspicious for mycobacterial infections," Clinical Microbiology and Infection, vol. 19, no. 8, pp. 723-728, 2013.

[3] M. Rahbar, A. Lamei, H. Babazadeh, and S. A. Yavari, "Isolation of rapid growing mycobacteria from soil and water in Iran," African Journal of Biotechnology, vol. 9, no. 24, pp. 3618-3621, 2010.

[4] H. Shojaei, P. Heidarieh, A. Hashemi, M. M. Feizabadi, and A. D. Naser, "Species identification of neglected nontuberculous Mycobacteria in a developing country," Japanese Journal of Infectious Diseases, vol. 64, no. 4, pp. 265-271, 2011.
[5] A. A. Velayati, M. R. Masjedi, P. Farnia et al., "Emergence of new forms of totally drug-resistant Tuberculosis bacilli: super extensively drug-resistant tuberculosis or totally drug-resistant strains in Iran," Chest, vol. 136, no. 2, pp. 420-425, 2009.

[6] D. Wagner and L. S. Young, "Nontuberculous mycobacterial infections: a clinical review," Infection, vol. 32 , no. 5, pp. 257270, 2004.

[7] V. M. Katoch, "Infections due to non-tuberculous mycobacteria (NTM)," Indian Journal of Medical Research, vol. 120, no. 4, pp. 290-304, 2004.

[8] M. E. Kimerling, J. Schuchter, E. Chanthol et al., "Prevalence of pulmonary tuberculosis among HIV-infected persons in a home care program in Phnom Penh, Cambodia," International Journal of Tuberculosis and Lung Disease, vol. 6, no. 11, pp. 988994, 2002.

[9] K. Gopinath and S. Singh, "Multiplex PCR assay for simultaneous detection and differentiation of Mycobacterium tuberculosis, Mycobacterium avium complexes and other Mycobacterial species directly from clinical specimens," Journal of Applied Microbiology, vol. 107, no. 2, pp. 425-435, 2009.

[10] Y. Kazumi and S. Mitarai, "The evaluation of an identification algorithm for Mycobacterium species using the 16S rRNA coding gene and rpoB,' International Journal of Mycobacteriology, vol. 1, no. 1, pp. 21-28, 2012. 
[11] K. Khan, J. Wang, and T. K. Marras, "Nontuberculous mycobacterial sensitization in the United States: national trends over three decades," American Journal of Respiratory and Critical Care Medicine, vol. 176, no. 3, pp. 306-313, 2007.

[12] M. J. van der Werf, C. Ködmön, V. Katalinić-Janković et al., "Inventorystudy of non-tuberculous mycobacteria in the European Union," BMC Infectious Diseases, vol. 14, article 62, 2014.

[13] S. Z. Bostanabad, P. Heidarieh, N. Sheikhi et al., "Identification of clinical isolates of Mycobacteria recovered from Iranian patients by phenotypic and molecular methods," New Cellular and Molecular Biotechnology Journal, vol. 2, no. 7, pp. 49-56, 2012 (Persian).

[14] F. Heidari, P. Farnia, J. Noroozi et al., "The rapid identification of a typical Mycobacterium in pulmonary tuberculosis (PTB) patients: evaluation of QUB3232 locus using the VNTR method," Journal of Zanjan University of Medical Sciences, vol. 17, no. 67, pp. 33-44, 2009 (Persian).

[15] S. Hadifar, S. Moghim, H. Gasemian-Safaei et al., "Identification of non-tuberculosis Mycobacteria isolates by polymerase chain reaction-restriction enzyme analysis of 360-bp fragment of rpoB gene," Journal of Isfahan Medical School, vol. 31, no. 266, p. 1, 2014 (Persian).

[16] T. Radaei, B. Nasr-Esfahani, H. Ghasemian-Safaei et al., "Ethambutol-susceptibility of clinical and environmental atypical Mycobacteria isolated from Isfahan, Iran," Journal of Isfahan Medical School, vol. 31, no. 234, pp. 1-7, 2013 (Persian).

[17] S. Moghim, B. N. Isfahani, N. Hosseini et al., "Identification of nontuberculous Mycobacteria isolated from Isfahan different water sources using phenotypic characterization tests," Journal of Water and Wastewater, vol. 25, no. 86, pp. 88-95, 2012 (Persian).

[18] B. N. Esfahani, E. Sarikhani, S. Moghim et al., "Molecular characterization of environmental non-tuberculous mycobacteria using PCR- RFLP analysis of $441 \mathrm{Bp}$ heat shock protein 65 fragments," Iranian Journal of Public Health, vol. 41, no. 4, pp. 108-114, 2012.

[19] P. Heidarieh, H. Shojaei, M. M. Feizabadi et al., "Molecular identification and conventional susceptibility testing of Iranian clinical Mycobacterium fortuitum isolates," Iranian Journal of Basic Medical Sciences, vol. 13, no. 1, pp. 210-215, 2010.

[20] M. Shafipour, M. Ghane, S. R. Alang et al., "Non tuberculosis Mycobacteria isolated from tuberculosis patients in Golestan province, North of Iran," Annals of Biological Research, vol. 4, no. 12, pp. 133-137, 2013.

[21] E. Ghaemi, K. Ghazisaidi, H. Koohsari, B. Khodabakhshi, and A. Mansoorian, "Environmental mycobacteria in areas of high and low tuberculosis prevalence in the Islamic Republic of Iran," Eastern Mediterranean Health Journal, vol. 12, no. 3-4, pp. 280$285,2006$.

[22] A. D. Khosravi, S. Seghatoleslami, and M. Hashenuadeh, "Application of PCR-based fingerprinting for detection of nontuberculous mycobacteria among patients referred to tuberculosis reference center of Khuzvstan Province, Iran," Research Journal of Microbiology, vol. 4, no. 4, pp. 143-149, 2009.

[23] M. Roayayi, K. Ghazisaidi, M. Jamshidian, and M. J. Kajbaf, "The abundance of non-tuberculous mycobacteria in tuberculosis suspected patients in Ahvaz," Journal of Ahvaz University of Medical sciences, no. 21, pp. 69-76, 1995 (Persian).

[24] A. Velayati, K. Ghazi-Saidi, A. Bashiri, Y. Dolati, M. Mohammadi, and J. Stanford, "The distribution of environmental mycobacteria in Gilan region," Journal of Medical Council of
Islamic Republic of IRAN, vol. 11, no. 3, pp. 173-179, 1992 (Persian).

[25] N. Naderi, E. Alavi-Naini, B. Sharifi-Mood, and M. Naserfar, "Prevalence of tuberculosis and non tuberculosis Mycobacterium in Zahedan, Southeast of Iran," Research Journal of Microbiology, vol. 1, no. 4, pp. 375-377, 2006.

[26] F. Fallah, A. Karimi, G. Eslami et al., "Isolation of Mycobacterium and other microorganism from skin infections in children during Bam earthquake," Iranian Journal of Clinical Infectious Diseases, vol. 2, no. 4, pp. 185-188, 2007.

[27] M. Marjani, M. Farshidpour, P. Tabarsi, F. M. Sheik Holslami, and P. Farnia, "Isolation of Mycobacterium branderi, an unusual species from an acute myelogenous leukemia patient," Avicenna Journal of Medicine, vol. 4, no. 1, pp. 17-19, 2014.

[28] F. Babamahmoodi, A. Babamahmoodi, and B. Nikkhahan, "Review of Mycobacterium marinum infection reported from Iran and report of three new cases with sporotrichoid presentation," Iranian Red Crescent Medical Journal, vol. 16, no. 2, Article ID e10120, 2014.

[29] H. Shojaei, C. Daley, Z. Gitti et al., "Mycobacterium iranicum sp. nov., a rapidly growing scotochromogenic species isolated from clinical specimens on three different continents," International Journal of Systematic and Evolutionary Microbiology, vol. 63, no. 4, pp. 1383-1389, 2013.

[30] P. Heidarieh, A. Hashemi-Shahraki, A. D. Khosravi, S. ZakerBoustanabad, H. Shojaei, and M. M. Feizabadi, "Mycobacterium arupense infection in HIV-infected patients from Iran," International Journal of STD \& AIDS, vol. 24, no. 6, pp. 485-487, 2013.

[31] S. Z. Bostanabad, P. Salehian, and A. H. Shahraki, "Isolation of Mycobacterium chelonae in the sputum and cervical lymph nodes of patient with metastatic breast cancer," Mycobacterial Diseases, vol. 2, article 106, 2013.

[32] B. Honarvar, H. Movahedan, M. Mahmoodi, F. M. Sheikholeslami, and P. Farnia, "Mycobacterium aurum keratitis: an unusual etiology of a sight-threatening infection," Brazilian Journal of Infectious Diseases, vol. 16, no. 2, pp. 204-208, 2012.

[33] F. Pourahmad, H. Shojaei, P. Heidarieh, A. Khosravi, and A. Hashemi, "Report of two cases of Mycobacterium europaeum from Iran," Japanese Journal of Infectious Diseases, vol. 65, no. 6, pp. 539-541, 2012.

[34] M. Alaeen, A. Z. Alaeen, and H. Alaeen, "A case report of fish tank granuloma in Khomein," Arak Medical University Journal, vol. 14, no. 57, pp. 113-117, 2011.

[35] S. M. H. Fard, M. R. Yossefi, B. Esfandiari, and S. A. A. Sefidgar, "Mycobacterium marinum as a cause of skin chronic granulomatous in the hand," Caspian Journal of Internal Medicine, vol. 2, no. 1, pp. 198-200, 2011.

[36] H. Shojaei, A. Hashemi, P. Heidarieh, N. Hosseini, and A. D. Naser, "Chronic pulmonary disease due to Mycobacterium monacense infection: the first case from Iran," Annals of Laboratory Medicine, vol. 32, no. 1, pp. 87-90, 2012.

[37] H. Shojaei, A. Hashemi, P. Heidarieh, and A. Daei-Naser, "Chronic pelvic pain due to Mycobacterium parascrofulaceum in an Iranian patient: first report of isolation and molecular characterization from Asia," Brazilian Journal of Infectious Diseases, vol. 15, no. 2, pp. 186-187, 2011.

[38] M. Shamaei, M. Marjani, P. Farnia, P. Tabarsi, and D. Mansouri, "Human infections due to Mycobacterium lentiflavum: first report in Iran," Iranian Journal of Microbiology, vol. 2, no. 1, pp. 29-31, 2010.

[39] M. Golpour and M. Ghasemi, "Nodules and bullae on the back of the hand with axillary spread. Diagnosis: fish tank or 
swimming pool granuloma," Indian Journal of Dermatologists, Venereologists and Leprologists, vol. 74, no. 5, p. 551, 2008.

[40] M. Boloorsaz, S. Khalilzadeh, P. Farnia, S. Hakimi, and A. A. Velayati, "Mycobacterium thermoresistibile infection in a child," Tanaffos, vol. 5, no. 3, pp. 61-63, 2006.

[41] WHO TB burden estimates, http://www.who.int/tb/country/ data/download/en/.

[42] Global tuberculosis report 2013, http://www.who.int/tb/publications/global_report/en/.

[43] N. Akhtar, A. Bari, and K. Nomani, "Incidence of typical and a typical mycobacteria in pulmonary infections at Lahore-a study of 500 cases," Journal of the Pakistan Medical Association, vol. 34, no. 4, pp. 84-87, 1984.

[44] T. Khanum, S. A. Rasool, M. Ajaz, and A. I. Khan, "Isolationdrug resistance profile and molecular characterization of indigenous typical and atypical mycobacteria," Pakistan Journal of Pharmaceutical Sciences, vol. 24, no. 4, pp. 527-532, 2011.

[45] I. Ahmed, K. Jabeen, and R. Hasan, "Identification of nontuberculous mycobacteria isolated from clinical specimens at a tertiary care hospital: a cross-sectional study," BMC Infectious Diseases, vol. 13, no. 1, article 493, 2013.

[46] K. I. Hassan and A. A. Ali, "Detection of Mycobacterium avium in milk powder using species specific PCR," International Journal of Advanced Science and Engineering Technology, vol. 2, no. 2, pp. 115-119, 2012.

[47] A. A. Al-Sulami, A. M. R. Al-Taee, and Q. H. Wida'a, "Isolation and identification of Mycobacterium avium complex and other nontuberculosis mycobacteria from drinking-water in Basra governorate, Iraq," Eastern Mediterranean Health Journal, vol. 18, no. 3, pp. 274-278, 2012.

[48] A. M. Hamzah, "Mycobacterium Spp. isolated from horses fecal samples," International Journal of Medicineand Pharmaceutical Sciences, vol. 3, no. 3, pp. 23-28, 2013.

[49] E. Tortoli, A. Mariottini, and G. Mazzarelli, "Evaluation of INNO-LiPA MYCOBACTERIA v2: improved reverse hybridization multiple DNA probe assay for mycobacterial identification," Journal of Clinical Microbiology, vol. 41, no. 9, pp. 4418-4420, 2003.

[50] I. Joao, P. Cristovao, L. Antunes, B. Nunes, and L. Jordao, "Identification of nontuberculous mycobacteria by partial gene sequencing and public databases," International Journal of Mycobacteriology, vol. 3, no. 2, pp. 144-151, 2014.

[51] Z. Derakhshani Nezhad, P. Farnia, F. M. Sheikholeslami et al., "A survey prevalence of non-tuberculosis mycobacteria from patients referred in Mycobacteriology Research Center of Iran," Journal of Kordestan University of Medical Sciences, vol. 19, pp. 31-39, 2014 (Persian).

[52] S. Rahideh, P. Farnia, and M. Darbouy, "Isolation and identification of rapidly growing Mycobacteria from water and soil by PCR-RFLP method in Robat Karim," Journal of Health, vol. 4, no. 4, pp. 321-329, 2013 (Persian).

[53] P. Baghaei, P. Tabarsi, P. Farnia et al., "Pulmonary disease caused by Mycobacterium simiae in Iran's national referral center for tuberculosis," Journal of Infection in Developing Countries, vol. 6, no. 1, pp. 23-28, 2012.

[54] A. Hashemi-Shahraki, D. Darban-Sarokhalil, P. Heidarieh et al., "Mycobacterium simiae: a possible emerging pathogen in Iran," Japanese Journal of Infectious Diseases, vol. 66, no. 6, pp. 475479, 2013.

[55] K. Yoshimura, M. Imao, H. Goto et al., "A case of pulmonary infection due to Mycobacterium simiae," Nihon Kokyūki Gakkai Zasshi, vol. 43, no. 1, pp. 32-36, 2005 (Japanese).
[56] Z. P. Önen, Z. C. Karahan, Ö. A. Yildiz, and G. Karabiyikoğlu, "Mycobacterium simiae infection in an immunocompetent patient, with DNA analyses verification," Tüberküloz ve Toraks, vol. 58, no. 3, pp. 306-310, 2010.

[57] M. J. van der Werf, C. Ködmön, V. Katalinić-Janković et al., "Inventory study of non-tuberculous mycobacteria in the European Union," BMC Infectious Diseases, vol. 14, no. 1, article 62, 2014. 


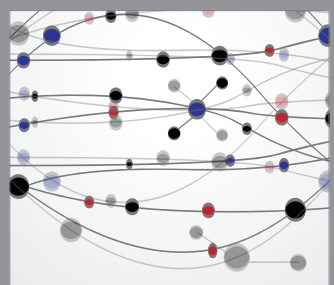

The Scientific World Journal
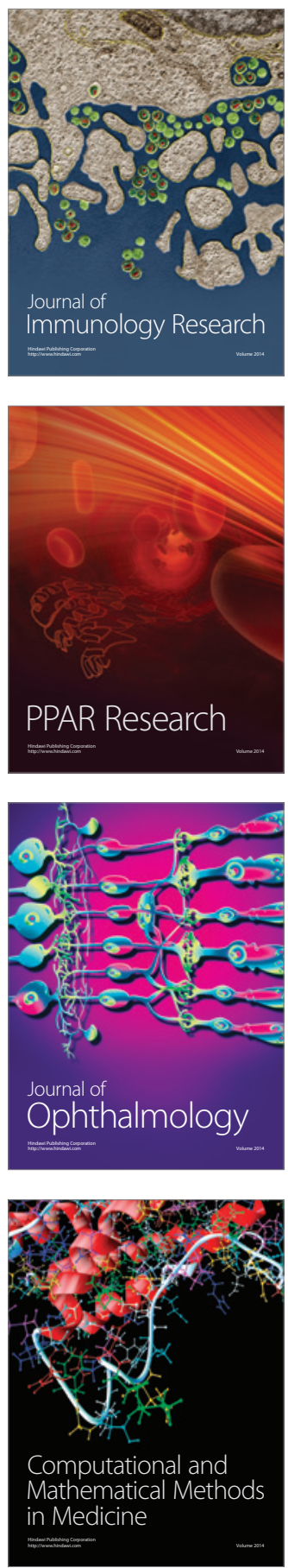

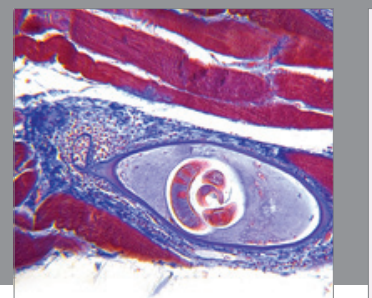

Gastroenterology

Research and Practice
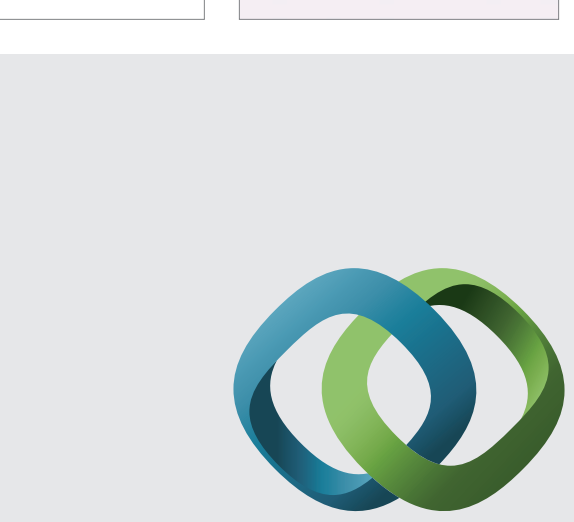

\section{Hindawi}

Submit your manuscripts at

http://www.hindawi.com
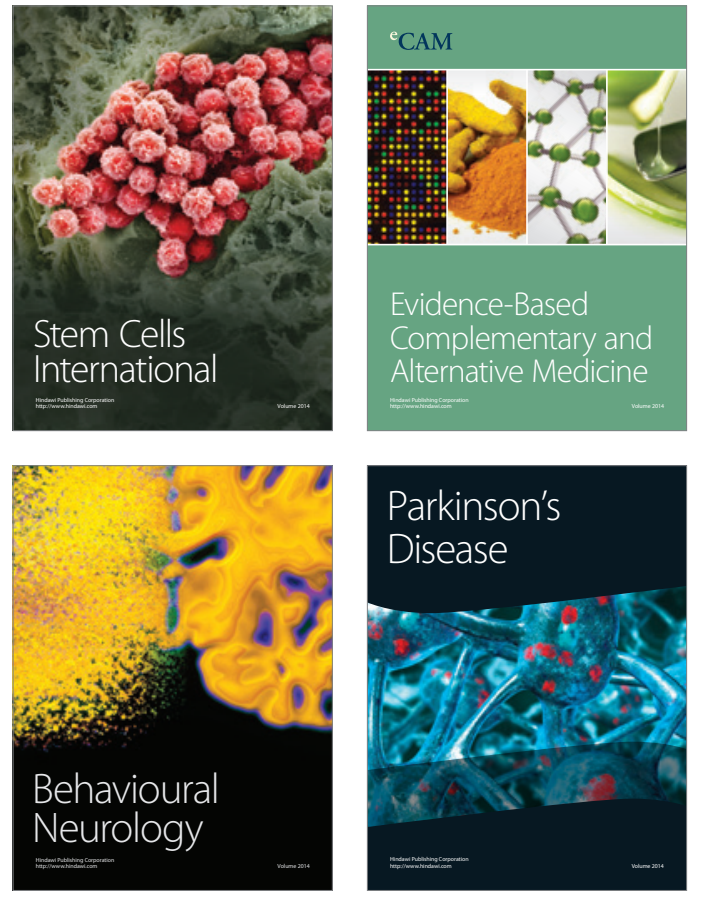
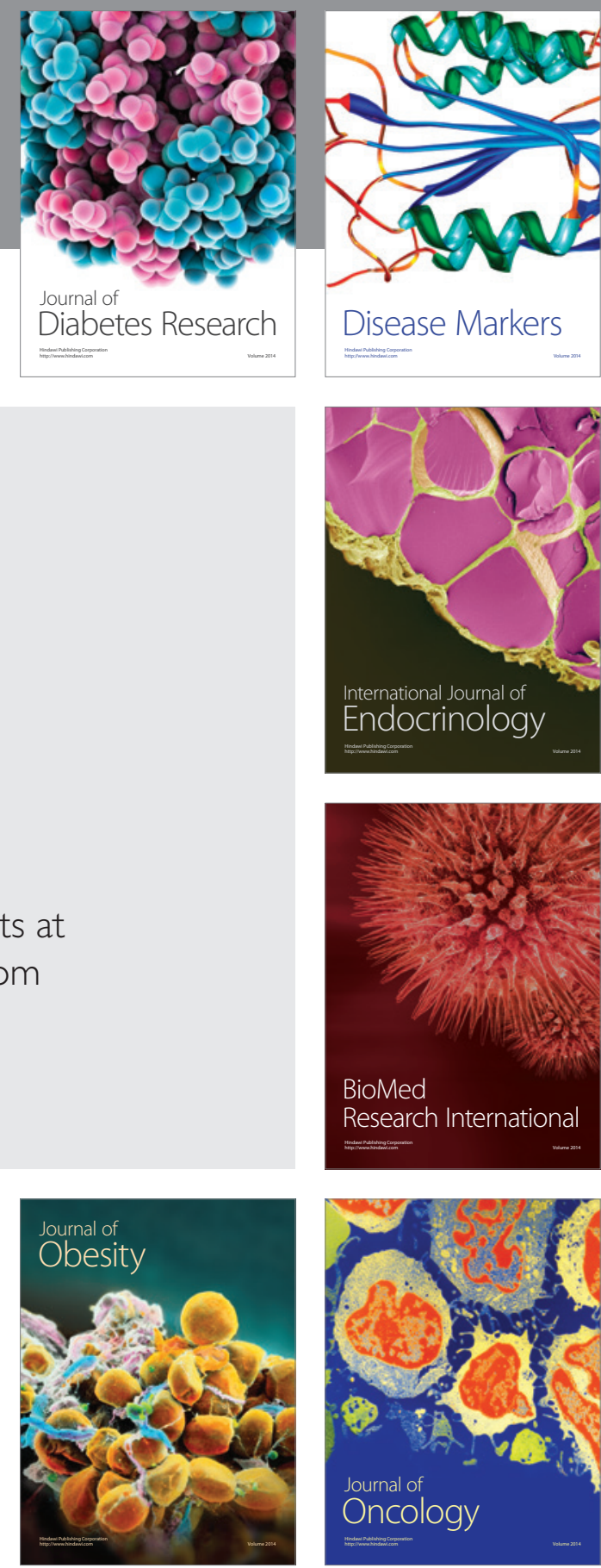

Disease Markers
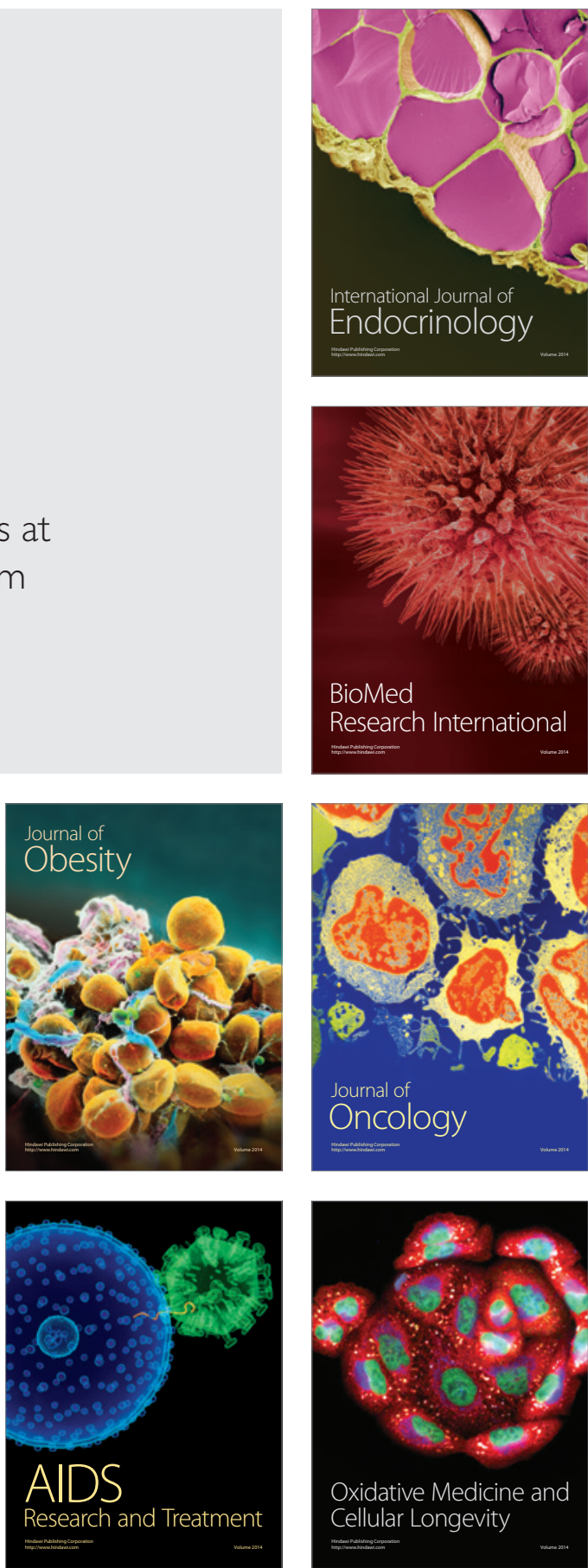